\title{
Circulating and Disseminated Tumor Cells in Breast Carcinoma
}

Report from the Consensus Conference on Tumor Cell Dissemination during the

39th Annual Meeting of the German Society of Senology, Berlin, 27 June 2019

\section{Zirkulierende und disseminierte Tumorzellen beim Mammakarzinom}

\author{
Bericht von der Konsensuskonferenz Tumorzelldissemination im Rahmen der \\ 39. Jahrestagung der Deutschen Gesellschaft für Senologie, Berlin, 27.06.2019
}

\section{(우요용}

Authors

Malgorzata Banys-Paluchowski ${ }^{1}$, Tanja Fehm², Wolfgang Janni ${ }^{3}$, Erich-Franz Solomayer ${ }^{4}$, Andreas Hartkopf ${ }^{5}$

Affiliations

1 Frauenklinik, Asklepios-Klinik Barmbek, Hamburg, Germany

2 Klinik für Frauenheilkunde und Geburtshilfe, Universitätsklinikum Düsseldorf, Düsseldorf, Germany

3 Frauenklinik, Universitätsklinikum Ulm, Ulm, Germany

4 Klinik für Frauenheilkunde, Geburtshilfe und Reproduktionsmedizin, Universitätsklinikum des Saarlandes, Homburg/Saar, Germany

5 Universitäts-Frauenklinik, Universitätsklinikum Tübingen, Tübingen, Germany

Key words

tumor cell dissemination, circulating tumor cell, disseminated tumor cell, prognostic factor, breast cancer

Schlüsselwörter

Tumorzelldissemination, zirkulierende Tumorzellen, disseminierte Tumorzelle, Prognosefaktor, Mammakarzinom

received $\quad 15.9 .2019$

revised $\quad 17.10 .2019$

accepted 18.10.2019

Bibliography

DOI https://doi.org/10.1055/a-1031-1120

Geburtsh Frauenheilk 2019; 79: 1320-1327 @ Georg Thieme

Verlag KG Stuttgart · New York I ISSN 0016-5751

Correspondence

Prof. Dr. med. A. Hartkopf

Universitäts-Frauenklinik, Universitätsklinikum Tübingen

Calwerstraße 7, 72076 Tübingen, Germany

andreas.hartkopf@uni-tuebingen.de

\section{ABSTRACT}

Hematogenous dissemination of single tumor cells from the primary tumor is a common phenomenon in most solid malignancies. In breast cancer, presence of circulating tumor cells (CTCS) in the peripheral blood and disseminated tumor cells (DTCs) in bone marrow predicts poor clinical outcome, both in early and metastatic setting. Beyond that, persistence of CTCs/DTCs is associated with shorter relapse-free interval as well. Numerous studies have shown that these cells differ from tumor cells in the primary tumor with regard to hormone and HER2 receptor status and it has been hypothesized that some of them might be in fact cancer stem cells. Recently, the first positive study on CTC-based therapy interventions has been presented at the San Antonio Breast Cancer Symposium 2018, demonstrating that detection of CTCS may guide treatment decisions in metastatic HR-positive HER2-negative disease. In this review, we present the current state of evidence of tumor cell dissemination and discuss the implications for future trials.

\section{ZUSAMMENFASSUNG}

Die hämatogene Dissemination vereinzelter Tumorzellen aus dem Primärtumor ist ein weitverbreitetes Phänomen bei den meisten soliden Malignomen. Beim Mammakarzinom weisen zirkulierende Tumorzellen (ZTZ) im peripheren Blut und disseminierte Tumorzellen (DTZ) im Knochenmark auf eine schlechte klinische Prognose hin, sowohl im Frühstadium als auch bei der metastasierten Erkrankung. Darüber hinaus ist der Nachweis von ZTZ/DTZ auch mit kürzeren rezidivfreien Intervallen assoziiert. Zahlreiche Studien haben gezeigt, dass sich diese Zellen hinsichtlich ihres Hormon- und HER2-Rezeptor-Status von den Tumorzellen des Primärtumors unterscheiden, und es wurde die Hypothese aufgestellt, dass einige von ihnen in Wirklichkeit Tumorstammzellen sein könnten. Vor Kurzem wurde anlässlich des 2018 San Antonio Breast Can- 
cer-Symposiums die erste positive Studie über ZTZ-basierende Therapien vorgestellt, die zeigte, dass der Nachweis von ZTZ die Wahl der Behandlungsmethode beim metastasierten HRpositiven HER2-negativen Mammakarzinom beeinflussen kann. In diesem Übersichtsartikel stellen wir den aktuellen Stand zum Nachweis der Tumorzelldissemination vor und diskutieren die Implikationen für künftige Studien.

\section{Introduction}

Dissemination of single cancer cells via blood stream is currently considered a crucial step during metastatic cascade. Historically, the first report on tumor cells in peripheral blood from a patient with a solid tumor has been published 150 years ago by Thomas Ashworth, a Melbourne-based surgeon ( $\triangleright$ Fig. 1) [1]. Since then, an extensive body of evidence has been accumulated on the relevance and the biological meaning of hematogenous cancer spread. Isolated tumor cells are generally referred to as circulating tumor cells (CTCs) in the peripheral blood or disseminated tumor cells (DTCs) when encountered in bone marrow or other organs. In recent years, studies have shown with level 1 evidence that both CTCs and DTCs predict worse clinical outcome in early and metastatic setting [2-5].
Currently, numerous translational research projects are investigating this issue in breast cancer. Among 58 clinical trials registered at ClinicalTrials.gov and EudraCT which are recruiting or planned, the vast majority (53) focuses on CTCs in the blood, with only five trials designed to explore DTCs in the bone marrow. $41 \%$ of the trials are being conducted in the United States of America, followed by China (12\%) and Germany (10\%). A smaller number of studies has been initiated in France (9\%) and Sweden (5\%) ( $\triangleright$ Fig. 2). Only four trials are phase III studies: two of them are based in Germany (DETECT III and DETECT V), one in India and one in China.

Beyond prognostication and therapy monitoring, CTC/DTCguided treatment decisions are considered the most exciting potential of tumor cell dissemination. In 2018, results from the first positive trial on therapy based on CTC status were presented at

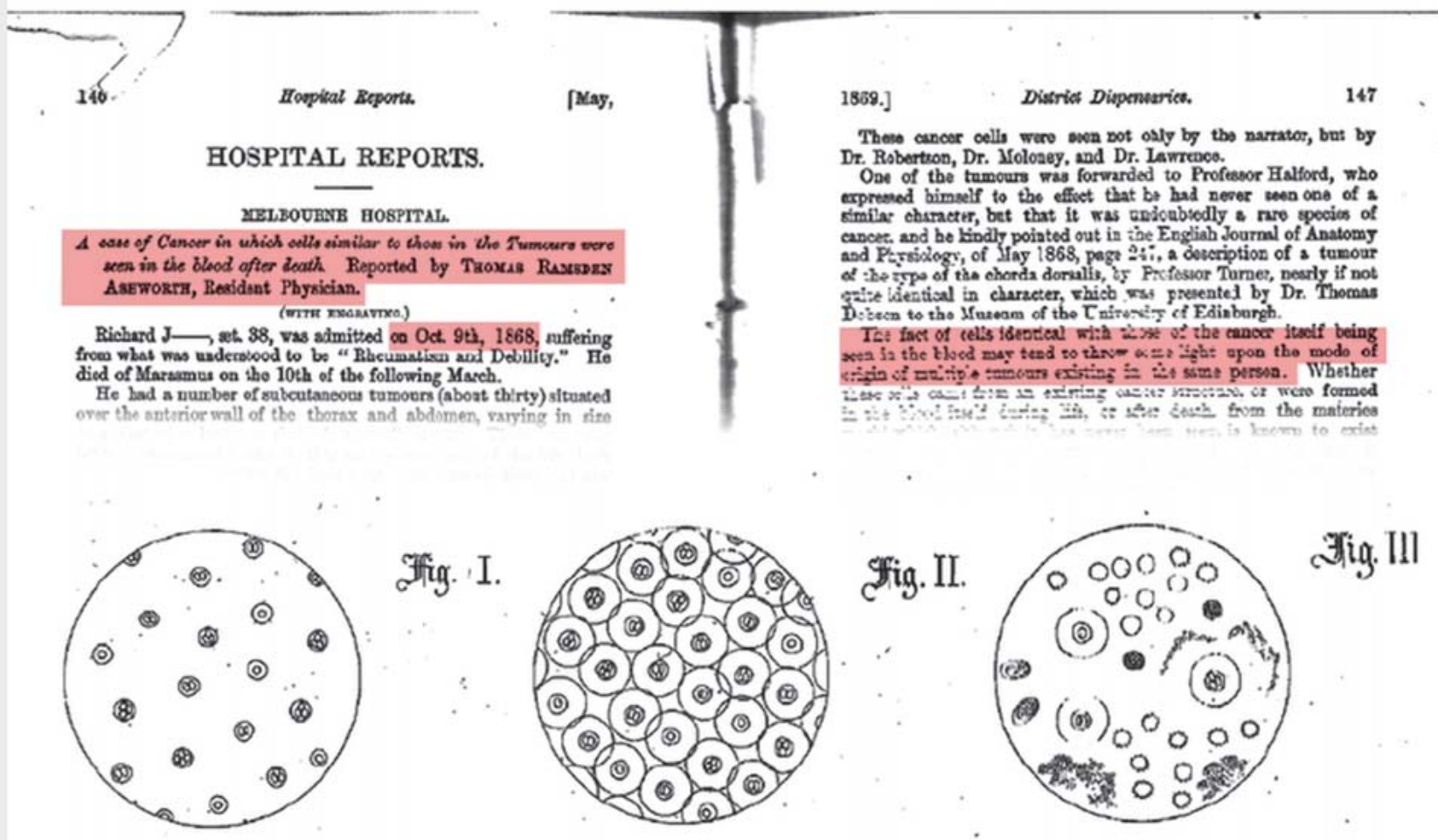

- Fig. 1 First page of the publication "A case of cancer in which cells similar to those in the Tumours were seen in the blood after death" including the first description of circulating tumor cells in 1869 [1]. 


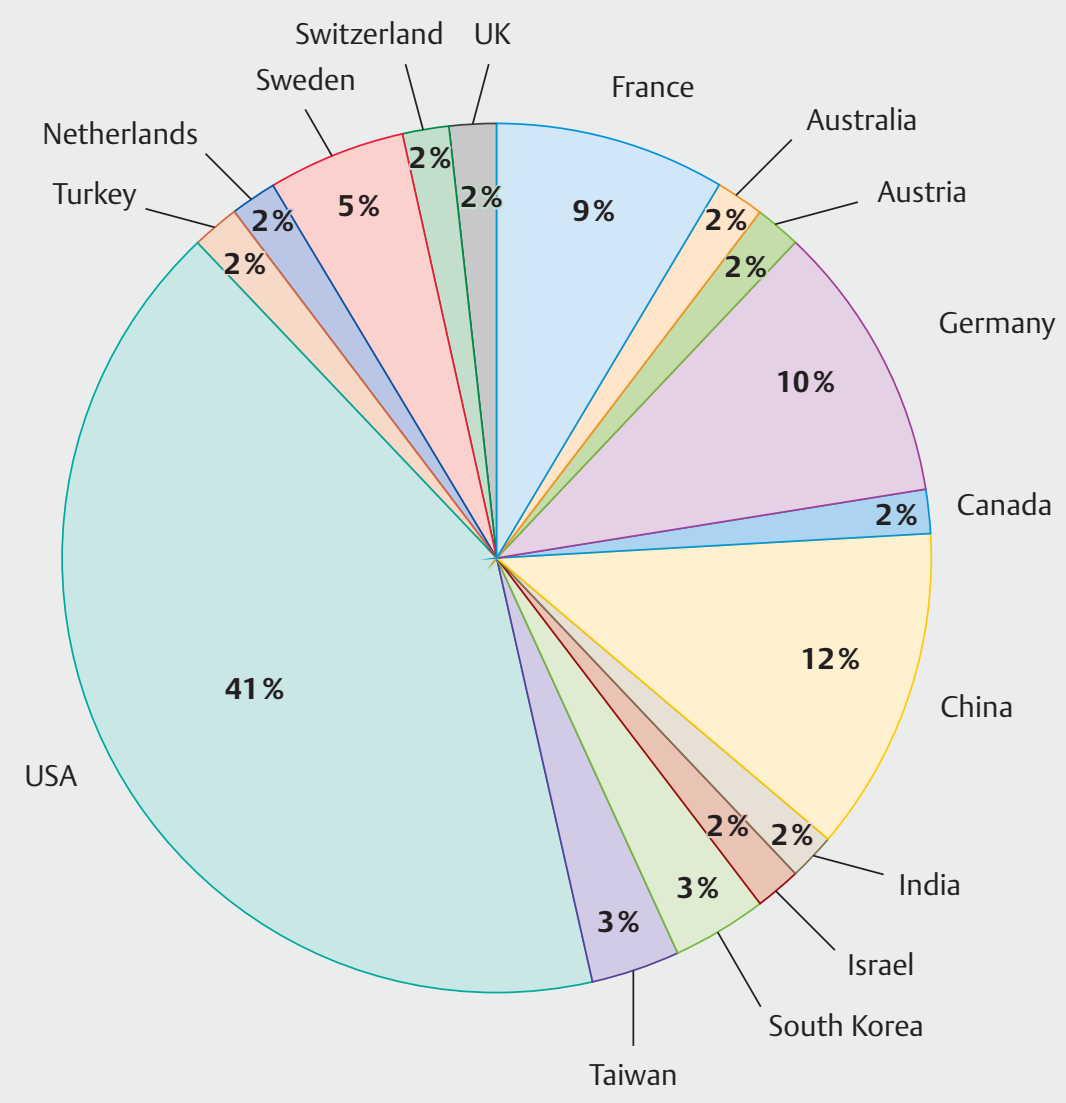

- Fig. 2 Circulating and disseminated tumor cell - current study landscape with an overview of open or planned clinical trials registered at ClinicalTrials.gov and EudtraCT.

the San Antonio Breast Cancer Symposium [6]. These and data from other studies have been recently thoroughly discussed at the yearly Consensus Conference on Tumor Cell Dissemination during the Annual Meeting of the German Society of Senology. In this review, we comment on the current data on hematogenous tumor cell dissemination and its possible clinical applications in the near future.

\section{Early Breast Cancer}

Two large meta-analyses confirmed that presence of CTCs or DTCs in patients with non-metastatic breast cancer (BC) is associated with poor survival $[2,4]$. Similarly, patients with persistent CTCs/ DTCs after completion of (neo)adjuvant chemotherapy are more at risk for developing a relapse $[7,8]$. Recently, two studies have investigated whether a blood-test performed during routine follow-up in asymptomatic patients may identify those with particularly poor prognosis.

The first analysis was conducted by Sparano et al. on a large group of HER2-negative BC patients participating in the ECOGACRIN trial E5103 $[9,10]$. This trial was originally designed to explore the use of bevacizumab in combination with adjuvant chemotherapy. 546 patients presented for blood sampling five years after diagnosis. In $4.8 \%$ of cases at least one CTC was detected per $7.5 \mathrm{ml}$ blood by using the CellSearch assay. In the subgroup of 353 patients with hormone receptor (HR-)positive disease, the recurrence rates per person-year of follow-up in the CTC-positive and CTC-negative groups were 21.4 and $2.0 \%$, respectively. In the multivariate analysis, a positive $\mathrm{CTC}$ result was associated with a 13.1-fold higher risk of recurrence.

Similar results were reported by the German SUCCESS-A trial [11]. In this phase III trial patients with high-risk BC were first randomized to 3 cycles of epirubicin-fluorouracil-cyclophosphamide followed by either 3 cycles of docetaxel or 3 cycles of gemcitabine-docetaxel, followed by a second randomization to 2 vs. 5 years of zoledronate treatment. Presence of CTCs five years after chemotherapy was assessed using the CellSearch system. At least one CTC was detected in $7.8 \%$ of patients. In HR-positive patients, CTC status was a significant prognostic factor for recurrence-free survival (hazard ratio 5.14 in the univariate and 5.95 in the multivariate analysis, respectively).

These two trials showed for the first time that the remaining relapse risk after BC treatment can be assessed using CTC detection. Future studies will clarify which strategies, e.g. intensified follow-up or extended adjuvant endocrine therapy, should be offered to patients with CTC persistence. 
Next to therapy monitoring and estimating prognosis, CTC detection might be used to predict therapy benefit. Retrospective analyses of NSABP-B31 and NCCTG-N9831 have suggested that some patients might benefit from HER2-directed treatment even though they have HER2-negative disease $[12,13]$. Using CTC detection, the phase II Treat-CTC trial aimed to identify these HER2-negative early BC patients that might respond to additional trastuzumab therapy. Patients with centrally confirmed HER2 nonamplified primary tumors and at least one CTC per $15 \mathrm{ml}$ blood (CellSearch assay) following surgery and (neo)adjuvant chemotherapy were randomized $(1: 1)$ to receive either 6 cycles of trastuzumab or 18 weeks of observation. Primary endpoint was the CTC detection rate $(\geq 1 \mathrm{CTC} / 15 \mathrm{ml}$ blood vs. no detectable CTCs) 18 weeks after randomization [14]. Secondary endpoints were invasive disease-free survival (iDFS) and cardiac safety. Of 1317 patients screened 95 (7.2\%) were CTC-positive. Sixty-three of these patients were randomized to trastuzumab (31 patients) and observation (32 patients). At week 18, 5 out of 31 patients that had received trastuzumab and 4 out of 32 in the observation arm were still CTC-positive $(p=0.765)$. The study was stopped due to the recommendations of an independent data committee after a median follow-up of 13 months. One-year iDFS was $93.8 \%$ (95\% Cl 77.3-98.4) in the observation vs. $84.8 \%$ (95\% Cl 63.494.2 ) in the trastuzumab arm. Several limitations might explain the negative results of Treat-CTC. First, only few patients were randomized and the CTC detection rate at week 18 was low. Second, results were biased by the use of endocrine treatment in hormone receptor-positive patients and third, CTCs were merely enumerated but not further characterized. As results of the NSABP-B47 trial recently demonstrated that there is no benefit for adjuvant trastuzumab in patients with HER2-negative tumors [15], determination of HER2 amplification in CTCs might help to more precisely guide HER2-targeted treatment. This concept is currently addressed by the German DETECT studies in the metastatic setting (see below).

A major limitation of using CTCs to estimate prognosis or predict treatment efficacy is their low detection rate in early breast cancer. Detection of single disseminated tumor cells (DTCs) in the bone marrow is an alternative approach that is feasible especially at the time-point of primary surgery: after bone marrow aspiration from the iliac crest, DTCs are generally detected by isolation of mononuclear cells, immunocytochemistry (pan-cytokeratin staining) and cytomorphologic criteria [16]. To confirm their prognostic relevance, a large pooled analysis (PADDY) was presented at the 2018 San Antonio Breast Cancer Symposium [17]. Individual patient data from 10307 patients, derived from 11 centers across Europe and the U.S., was analyzed. Of all patients included, $2814(27.3 \%)$ had at least one detectable DTC. The proportion of DTC-positive patients was higher in patients with larger tumor burden (tumor size, lymph node involvement, $\mathrm{p}<0.001$ ) or more aggressive tumor (ER/PR negativity, HER2 positivity or higher grading, $p<0.001)$. DTC detection was significantly associated with an impaired prognosis: after a median follow-up of 7.6 years the multivariate hazard ratios $(\mathrm{HR} ; 95 \% \mathrm{Cl})$ were 1.23 (1.06-1.43; $\mathrm{p}<0.006)$ for overall survival (OS) and $1.30(1.12-1.52, \mathrm{p}<0.001)$ for disease-free survival (DFS). There was a statistically significant interaction between biological tumor subtype and DTC-positivity $(p=0.014)$ and the prognostic impact was especially pronounced in Luminal B (defined as ER/PR-positive, HER2-negative and G3) patients. Additionally, it was shown previously that DTCs are already detectable in patients with pre-invasive breast cancer (i.e. ductal carcinoma in situ, DCIS) $[18,19]$. These results emphasize the hypothesis of parallel tumor progression where metastatic disease derives from single cells that migrate and disseminate from very early breast cancer lesions [20,21]. Future trials should now investigate whether DTC detection is useful to tailor adjuvant treatment. For example the HER2 expression of DTCs differs from that of the primary tumor and patients with HER2-positive DTC have an increased risk of metastatic relapse and might therefore benefit from trastuzumab treatment $[22,23]$. Moreover, DTC detection seems to predict efficacy of bone-targeted therapy. The prospective MRD-1 trial found that zoledronic acid might eliminate DTCs from the bone marrow and a retrospective analysis of a large data-set revealed that bisphosphonates are more effective for the prevention of distant metastasis in DTC-positive patients [24-26]. Currently there are prospective trials ongoing to evaluate the effect of denosumab in DTC-positive patients (NCT01545648, NCT02682693).

\section{Metastatic Breast Cancer}

In the last two decades, numerous studies have confirmed presence of CTCs in patients with metastatic BC as a strong independent prognostic factor $[3,27,28]$. Due to large numbers of CTCS encountered in patients with advanced disease, the cutoff of 5 CTCs per $7.5 \mathrm{ml}$ blood is usually used in case of CellSearch-based detection (in contrast to early BC, where patients with at least one CTC are referred to as CTC-positive) [29]. Recently, Cristofanilli et al. evaluated CTC samples from 2436 women with metastatic BC from 17 European centers participating in the European Pooled Analysis Consortium and a single large U.S. institution, the MD Anderson Cancer Center in a pooled analysis [30]. Patients with $<5$ CTCs per $7.5 \mathrm{ml}$ blood had significantly longer median OS than those with $\geq 5$ CTCs (36.3 vs. 16.0 months, $p<0.0001$ ). This association was independent of the tumor subtype, prior treatment and disease location.

In most patients, CTC counts decline rapidly after start of systemic therapy. However, patients with persistently high CTC numbers are significantly more at risk for relapse [31]. Martin et al. measured CTCs in patients receiving palliative chemotherapy and reported that CTC numbers after the first cycle of treatment were associated with response to therapy and survival in the multivariate analysis [32]. Thus, CTC dynamics are able to predict whether the patients will benefit from therapy sooner than conventional radiological imaging. However, it remains unclear which therapeutic strategy should be offered to non-responders. In the SWOG 0500 trial, blood samples were evaluated before and during first-line chemotherapy in 595 patients [31]. Out of these, 123 patients had increased CTC counts both prior to therapy and after the first cycle and were randomized either to continue treatment or switch to another chemotherapy regimen ( $\triangleright$ Fig. 3). PFS and OS were similar in both arms. Possibly, CTC persistence identifies patients resistant to conventional chemotherapy, indepen- 


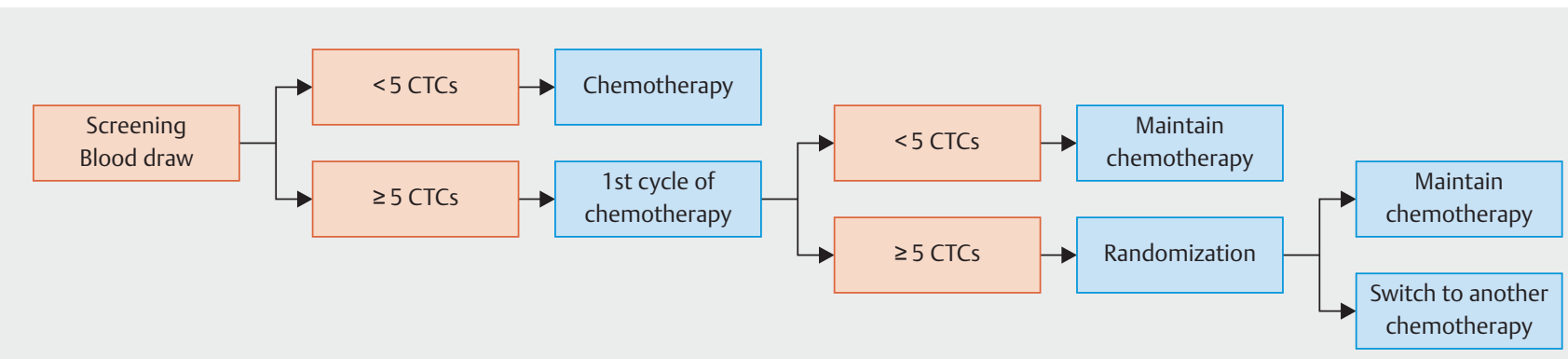

- Fig. 3 Study design of the SWOG 0500 trial (A Randomized Phase III Trial to Test the Strategy of Changing Therapy Versus Maintaining Therapy for Metastatic Breast Cancer Patients who Have Elevated Circulating Tumor Cell Levels at First Follow-Up Assessment).

dent of the cytotoxic drug used, who might rather benefit from targeted or experimental treatment approach.

\section{CTC-guided Therapy Decisions in Metastatic Setting: Ready for Prime Time?}

In recent years, several studies have aimed at exploring the potential of CTCs to guide treatment in metastatic BC. Two large studies have been initiated in France (Institut Curie) and Germany (DETECT study group), respectively. While the DETECT trials are still recruiting, the results of the French STIC CTC trial were presented at the San Antonio Breast Cancer Symposium 2018 [6]. This study was designed to investigate whether CTC counts may select optimal therapy for patients with HR-positive HER2-negative metastatic disease ( Fig. 4). 778 patients were randomized before start of first-line therapy: in the standard arm patient's oncologist decided whether the patient was suitable for endocrine therapy or chemotherapy; in the experimental arm the treatment was based on the CTC numbers. In about half of the patient population, a concordant low risk estimate was obtained (i.e. clinically low risk and < 5 CTCs per $7.5 \mathrm{ml}$ blood). These patients received endocrine therapy in both the control arm and the CTC arm. At the other side of the spectrum were $13.5 \%$ of patients whose clinical risk estimation and the blood test both showed high risk situation (i.e. clinically high risk and $\geq 5$ CTCs); these patients received chemotherapy in both arms. In between, in about $40 \%$ of the population, the risk estimation (clinical vs. blood-based) was discordant and patients received either endocrine therapy or chemotherapy according to their risk profiles and randomization arm.

The progression-free and overall survival were identical in both arms, showing that standardized CTC-based risk estimation was not inferior to the - often poorly reproducible - clinical assessment. Interestingly, in patients with discordant risk estimation (i.e. clinically low risk but $\geq 5$ CTCs or clinically high risk but $<5$ CTCS), the PFS and OS were significantly longer if patients received chemotherapy. Admittedly, the interpretation of these results is not easy: the STIC CTC trial was designed before the approval of CDK4/6 inhibitors and the majority of patients with HR-positive HER2-negative metastatic BC is now treated with endocrinebased combination treatment [33]. Having said that, the evidence provided by this trial demonstrates that assessment of CTC numbers is able to identify patients in need of a treatment more effective than endocrine monotherapy.

In contrast, the DETECT study program aims at investigating the influence of CTC characteristics - and not CTC counts - on response to therapy. Currently, the choice of systemic therapy in the metastatic setting is based on the properties of the primary tumor or metastasis. However, numerous studies have shown that expression profiles of CTCs may differ from both the primary tumor and distant metastasis [21,34,35]. The first phase III trial within this large translational project is the DETECT III study ( $\bullet$ Fig.5). In this trial, patients with HER2-negative metastatic BC are first screened for HER2-positive CTCs and, in case such cells are detected, randomized to standard therapy \pm HER2-targeted treatment with lapatinib. Patients with HER2-negative CTCs are offered several study options within the DETECT IV trials. Women with HER2-positive tumors may participate in the DETECT $\vee$ trial and receive dual anti-HER2 blockade in combination with either chemotherapy or endocrine therapy plus CDK4/6 inhibitor ribociclib.

\section{Conclusions}

In conclusion, the detection and characterization of CTCS and DTCs holds great promise to more precisely monitor and target the source of metastatic spread. For this purpose it is important to better understand the biological principles of tumor evolution. In the future, combining molecular characteristics (e.g. single cell sequencing) of CTCs and DTCs with clinical data, immunological markers and other forms of liquid biopsy (e.g. circulating tumor DNA or miRNA) might help to identify biomarkers or drugable targets to more precisely monitor and/or tailor systemic treatment.

\section{Conflict of Interest}

$\mathrm{AH}$ received an institutional research grant from GenomicHealth and honoraria from Roche, Novartis, Pfizer, Lilly and Amgen. MBP received lecture honoraria and served in advisory role for Roche, Novartis, Pfizer and Lilly. 


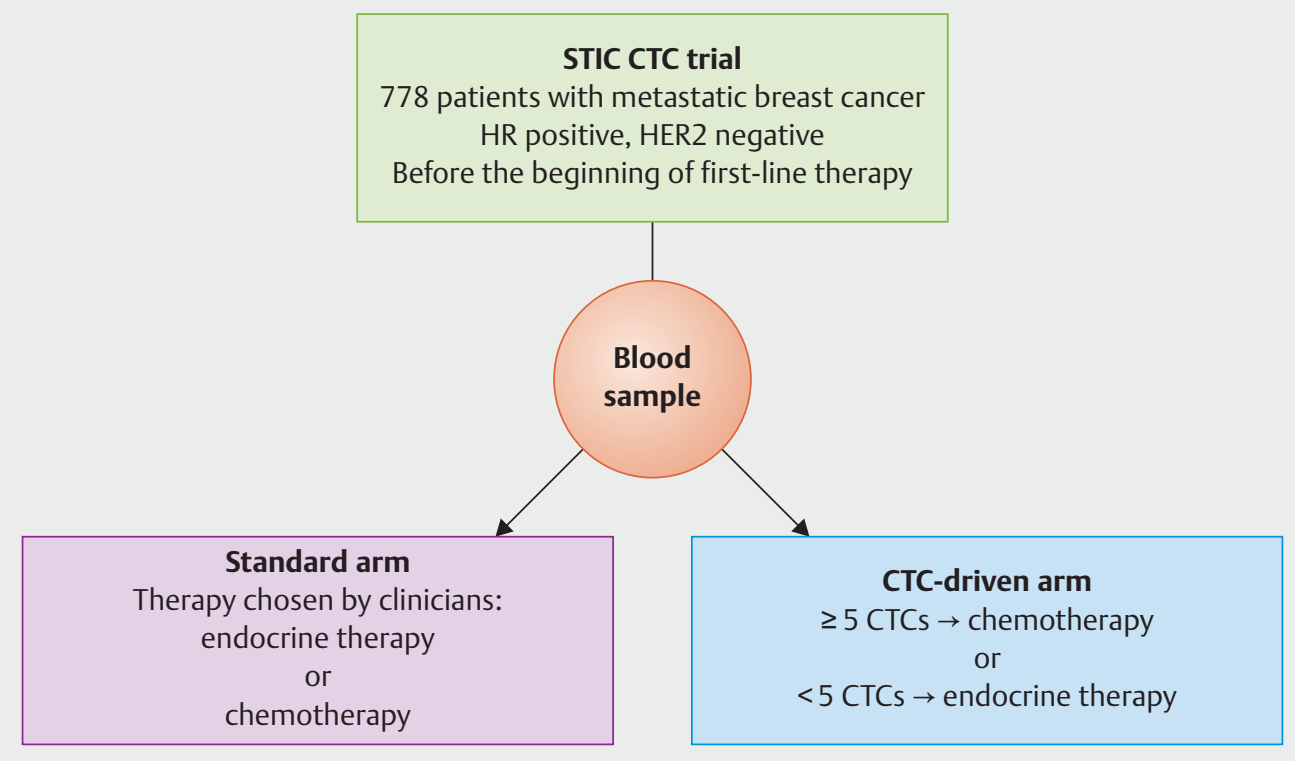

- Fig. 4 Design of the STIC CTC trial - the first positive study on CTC-based treatment interventions (Randomized Trial to Evaluate the Medicoeconomic Interest of Taking Into Account Circulating Tumor Cells to Determine the Kind of First Line Treatment for Metastatic, Hormone-receptors Positive, Breast Cancers).

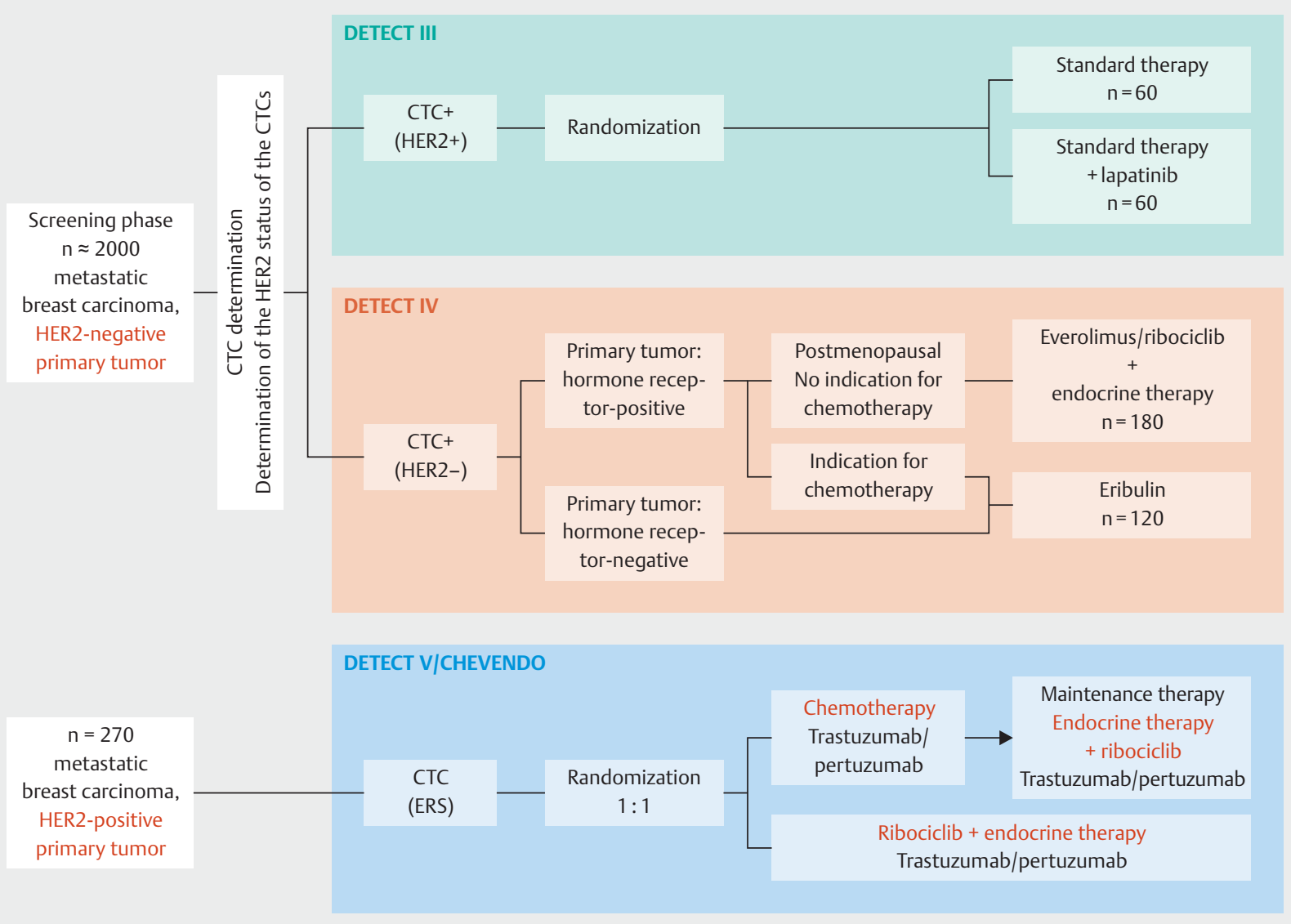

- Fig. 5 Study design of the DETECT trials - the largest study program on CTC-guided therapies worldwide [36]. 


\section{References}

[1] Ashworth TR. A case of cancer in which cells similar to those in tumors were seen in the blood after death. Aus Med J 1869; 14: 146-149

[2] Braun S, Vogl FD, Naume B et al. A pooled analysis of bone marrow micrometastasis in breast cancer. N Engl J Med 2005; 353: 793-802

[3] Bidard FC, Peeters DJ, Fehm T et al. Clinical validity of circulating tumour cells in patients with metastatic breast cancer: a pooled analysis of individual patient data. Lancet Oncol 2014; 15: 406-414

[4] Janni W], Rack B, Terstappen LW et al. Pooled Analysis of the Prognostic Relevance of Circulating Tumor Cells in Primary Breast Cancer. Clin Cancer Res 2016; 22: 2583-2593

[5] Bidard FC, Michiels S, Riethdorf S et al. Circulating Tumor Cells in Breast Cancer Patients Treated by Neoadjuvant Chemotherapy: A Meta-analysis. J Natl Cancer Inst 2018; 110: 560-567

[6] Bidard F-C, Jacot W, Dureau S et al. Abstract GS3-07: Clinical utility of circulating tumor cell count as a tool to chose between first line hormone therapy and chemotherapy for ER+ HER2- metastatic breast cancer: Results of the phase III STIC CTC trial. San Antonio Breast Cancer Symposium; December 4-8, 2018; San Antonio, Texas. Cancer Res 2019. doi:10.1158/1538-7445.SABCS18-GS3-07

[7] Rack B, Schindlbeck C, Jückstock J et al.; SUCCESS Study Group. Circulating tumor cells predict survival in early average-to-high risk breast cancer patients. J Natl Cancer Inst 2014; 106: pii: dju066

[8] Janni W, Vogl FD, Wiedswang G et al. Persistence of disseminated tumor cells in the bone marrow of breast cancer patients predicts increased risk for relapse-a European pooled analysis. Clin Cancer Res 2011; 17: 29672976

[9] Sparano JA, O’Neill A, Alpaugh K et al. Abstract GS6-03: Circulating tumor cells (CTCS) five years after diagnosis are prognostic for late recurrence in operable stage II-III breast cancer. San Antonio Breast Cancer Symposium; December 5-9, 2017; San Antonio, Texas. Cancer Res 2018. doi:10.1158/1538-7445.SABCS17-GS6-03

[10] Sparano J, O'Neill A, Alpaugh K et al. Association of Circulating Tumor Cells With Late Recurrence of Estrogen Receptor-Positive Breast Cancer: A Secondary Analysis of a Randomized Clinical Trial. JAMA Oncol 2018. doi:10.1001/jamaoncol.2018.2574

[11] Janni W, Rack B, Fasching P et al. Persistence of circulating tumor cells in high risk early breast cancer patients five years after adjuvant chemotherapy and late recurrence: Results from the adjuvant SUCCESS A trial. J Clin Oncol 2018; 36 (15_Suppl): 515

[12] Paik S, Kim C, Wolmark N. HER2 status and benefit from adjuvant trastuzumab in breast cancer. N Engl J Med 2008; 358: 1409-1411

[13] Perez EA, Reinholz MM, Hillman DW et al. HER2 and chromosome 17 effect on patient outcome in the N9831 adjuvant trastuzumab trial. J Clin Oncol 2010; 28: 4307-4315

[14] Ignatiadis M, Litière $S$, Rothe $F$ et al. Trastuzumab versus observation for HER2 nonamplified early breast cancer with circulating tumor cells (EORTC 90091-10093, BIG 1-12, Treat CTC): a randomized phase II trial. Ann Oncol 2018; 29: 1777-1783

[15] Fehrenbacher L, Cecchini R, Geyer C et al. Abstract GS1-02: NSABP B-47 (NRG oncology): Phase III randomized trial comparing adjuvant chemotherapy with adriamycin (A) and cyclophosphamide $(C) \rightarrow$ weekly paclitaxel (WP), or docetaxel (T) and C with or without a year of trastuzumab $(\mathrm{H})$ in women with node-positive or high-risk node-negative invasive breast cancer (IBC) expressing HER2 staining intensity of IHC 1+ or 2+ with negative FISH (HER2-Low IBC). Cancer Res 2018. doi:10.1158/ 1538-7445.SABCS17-GS1-02
[16] Fehm T, Braun S, Muller $V$ et al. A concept for the standardized detection of disseminated tumor cells in bone marrow from patients with primary breast cancer and its clinical implementation. Cancer 2006; 107: 885892

[17] Hartkopf AD, Brucker SY, Taran F-A et al. Abstract GS5-07: International pooled analysis of the prognostic impact of disseminated tumor cells from the bone marrow in early breast cancer: Results from the PADDY study. San Antonio Breast Cancer Symposium; December 4-8, 2018; San Antonio, Texas. Cancer Res 2019. doi:10.1158/1538-7445. SABCS18-GS5-07

[18] Walter VP, Taran FA, Wallwiener M et al. Abstract P1-01-16: Detection of disseminated tumor cells in DCIS patients impacts local recurrence. San Antonio Breast Cancer Symposium; December 5-9, 2017; San Antonio, Texas. Cancer Res 2018. doi:10.1158/1538-7445.SABCS17-P1-01-16

[19] Banys M, Hahn M, Gruber I et al. Detection and clinical relevance of hematogenous tumor cell dissemination in patients with ductal carcinoma in situ. Breast Cancer Res Treat 2014; 144: 531-538

[20] Hosseini H, Obradovic MM, Hoffmann M et al. Early dissemination seeds metastasis in breast cancer. Nature 2016. doi:10.1038/nature20785

[21] Klein CA. Parallel progression of primary tumours and metastases. Nat Rev Cancer 2009; 9: 302-312

[22] Rack B, Juckstock J, Gunthner-Biller M et al. Trastuzumab clears HER2/ neu-positive isolated tumor cells from bone marrow in primary breast cancer patients. Arch Gynecol Obstet 2012; 285: 485-492

[23] Hartkopf AD, Banys M, Meier-Stiegen F et al. The HER2 status of disseminated tumor cells in the bone marrow of early breast cancer patients is independent from primary tumor and predicts higher risk of relapse. Breast Cancer Res Treat 2013; 138: 509-517

[24] Solomayer EF, Gebauer G, Hirnle P et al. Influence of zoledronic acid on disseminated tumor cells in primary breast cancer patients. Ann Oncol 2012; 23: 2271-2277

[25] Hartkopf AD, Taran FA, Wallwiener M et al. Prognostic relevance of disseminated tumour cells from the bone marrow of early stage breast cancer patients - results from a large single-centre analysis. Eur J Cancer 2014; 50: 2550-2559

[26] Banys M, Solomayer EF, Gebauer $G$ et al. Influence of zoledronic acid on disseminated tumor cells in bone marrow and survival: results of a prospective clinical trial. BMC Cancer 2013; 13: 480

[27] Banys-Paluchowski M, Krawczyk N, Fehm T. Potential Role of Circulating Tumor Cell Detection and Monitoring in Breast Cancer: A Review of Current Evidence. Front Oncol 2016; 6: 255

[28] Janni W, Schneeweiss A, Muller V et al. Update Breast Cancer 2019 Part 2 - Implementation of Novel Diagnostics and Therapeutics in Advanced Breast Cancer Patients in Clinical Practice. Geburtsh Frauenheilk 2019; 79: $268-280$

[29] Cristofanilli M, Budd GT, Ellis M] et al. Circulating tumor cells, disease progression, and survival in metastatic breast cancer. $\mathrm{N}$ Engl J Med 2004; 351: 781-791

[30] Cristofanilli M, Pierga JY, Reuben J et al. The clinical use of circulating tumor cells (CTCs) enumeration for staging of metastatic breast cancer (MBC): International expert consensus paper. Crit Rev Oncol Hematol 2019; 134: 39-45

[31] Smerage JB, Barlow WE, Hortobagyi GN et al. Circulating tumor cells and response to chemotherapy in metastatic breast cancer: SWOG S0500. J Clin Oncol 2014; 32: 3483-3489

[32] Martin M, Custodio S, de Las Casas ML et al. Circulating tumor cells following first chemotherapy cycle: an early and strong predictor of outcome in patients with metastatic breast cancer. Oncologist 2013; 18 : 917-923 
[33] Huober ], Fasching PA, Taran F-A et al. Abstract P3-11-07: Factors associated with first line chemotherapy use in patients with hormone receptor positive, HER2 negative metastatic breast cancer - data from the PRAEGNANT breast cancer registry. San Antonio Breast Cancer Symposium; December 5-9, 2017; San Antonio, Texas. Cancer Res 2018. doi:10.1158/1538-7445.SABCS17-P3-11-07

[34] Banys M, Krawczyk N, Becker S et al. The influence of removal of primary tumor on incidence and phenotype of circulating tumor cells in primary breast cancer. Breast Cancer Res Treat 2012; 132: 121-129
[35] Pantel K, Brakenhoff RH. Dissecting the metastatic cascade. Nat Rev Cancer 2004; 4: 448-456

[36] Banys-Paluchowski M, Hartkopf A, Meier-Stiegen F et al. Circulating and Disseminated Tumour Cells in Breast Carcinoma: Report from the Consensus Conference on Tumour Cell Dissemination during the 38th Annual Meeting of the German Society of Senology, Berlin, 14 June 2018. Geburtsh Frauenheilk 2019; 79: 177-183 